\title{
HUBUNGAN ANTARA SENAM, POLA MAKAN, DAN DUKUNGAN KELUARGA DENGAN KUALITAS HIDUP PADA LANSIA
}

\author{
Suharno* Yophi Nugraha** Muhammad Guntur M***
}

\begin{abstract}
ABSTRAK
Meningkatnya usia harapan hidup (UHH) menyebabkan peningkatan jumlah lansia. Meningkatnya jumlah lansia menandakan kualitas hidup semakin baik. Jumlah lansia di Puskesmas Majalengka yaitu 2597 orang, sedangkan Puskesmas Cigasong dengan 1876 orang. Penelitian ini bertujuan untuk mengetahui hubungan antara Senam, Pola Makan dan Dukungan Keluarga dengan Kualitas Hidup pada Lansia di UPTD Puskesmas Majalengka Kabupaten Majalengka.

Jenis penelitian ini adalah kuantitatif dengan 97 responden lansia yang diambil secara Accidental Sampling. Rancangan penelitain ini adalah cross sectional. Pengumpulan data dilakukan dengan pengambilan data sekunder dan data primer. Analisis data yang digunakan yaitu analisis univariat dan bivariat.

Hasil penelitian ini menunjukan lebih dari setengahnya lansia mempunyai kualitas hidup tinggi $(73,2 \%)$, lebih dari setengahnya lansia rutin mengikuti senam $(62,9 \%)$, lebih dari setengahnya lansia mempunyai pola makan baik $(75,3 \%)$, dan sebagian besar lansia mendapatkan dukungan tinggi dari keluarganya $(76,3 \%)$. Hasil uji chi square pada penelitian ini menunjukan ada hubungan yang signifikan antara senam dengan kualitas hidup dengan nilai $\rho=0,000$; pola makan dengan kualitas hidup dengan nilai $\rho=0,000$; dan dukungan keluarga dengan kualitas hidup dengan nilai $\rho=0,000$.
\end{abstract}

Kata kunci : Lansia, Kualitas Hidup, Senam, Pola Makan, Dukungan Keluarga

\begin{abstract}
Increasing life expectancy causes an increase the number of elderly. Increasing the number of elderly indicates that quality of life is get better. The number of elderly in community health center Majalengka is 2597 people, while in community health center Cigasong is 1876 people. This research aims to determine the relationship between gymnastics, diet, and family motivation with quality of life of the elderly in community health center in Majalengka district.

This type of research is quantitative with 97 elderly respondents taken by accidental sampling. The design of this study is cross sectional design. Data collected by collection of secondary data and primary data. Data analysis was perfomed using univariate and bi-variate analysis.

Results in this study showed more than half of the elderly have high quality of life $(73,2 \%)$, more than half of the elderly routine follow gymnastics $(62,9 \%)$, more than half of the elderly have good diet $(75,3 \%)$, and most elderly get high motivation of his family $(76,3 \%)$. Chi square test results in this study showed there was a significant relationship between Gymnastics with quality of life with the $\rho$ value $=0,000$; Diet with quality of life with the $\rho$ value $=0,000$; and Family Motivation with quality of life with the $\rho$ value $=0,000$;
\end{abstract}

Keywords : Elderly, Quality of life, Gymnastics, Diet, Family Motivation

\footnotetext{
*Staf Pengajar Program Studi S1 Keperawatan YPIB Majalengka

** Staf Pengajar Program Studi S1 Keperawatan YPIB Majalengka

***Mahasiswa Program Studi S1 Keperawatan YPIB Majalengka
} 


\section{PENDAHULUAN}

Menurut WHO sehat adalah keadaan sejahtera secara fisik, mental dan sosial yang merupakan satu kesatuan, bukan hanya terbebas dari penyakit maupun cacat. ${ }^{1}$ Sejalan dengan definisi sehat menurut WHO, menurut Undang-Undang Kesehatan No. 36 Tahun 2009 sehat adalah keadaan sejahtera dari badan, jiwa, dan sosial sehingga memungkinkan setiap orang dapat hidup produktif secara sosial dan ekonomi.

Berdasarkan data WHO tentang World Population Ageing, diperkirakan terdapat sekitar 841 juta jiwa penduduk lanjut usia (lansia) di dunia pada tahun 2013. Berdasarkan data proyeksi penduduk, diperkirakan tahun 2015, terdapat 21,68 juta jiwa penduduk lansia di Indonesia $8,49 \%$ dari populasi penduduk, hal ini menunjukkan bahwa Indonesia termasuk negara yang akan memasuki era penduduk menua (ageing population) karena jumlah penduduknya yang berusia 60 tahun ke atas melebihi angka $7 \% .^{2}$

Menurut data dari BPS Jawa Barat, jumlah lansia yang berusia 60 tahun ke atas di jawa barat yaitu sebesar 3,03 juta atau $7 \%$ dari total 43 juta penduduk Jawa Barat. ${ }^{3}$ Berdasarkan data dari Dinas Kesehatan Kabupaten Majalengka tahun 2015 jumlah lansia di Kabupaten Majalengka sebanyak 145.562 jiwa atau 11,65\% dari jumlah total penduduk di Kabupaten Majalengka, di kabupaten majalengka sendiri terdapat 32 puskesmas yang tersebar di berbagai kecamatan. Berdasarkan data yang diperoleh dari Dinas Kesehatan Kabupaten Majalengka, Puskesmas dengan jumlah kunjungan lansia pada tahun 2016 terbanyak secara berturut-turut yaitu di Puskesmas Majalengka yaitu dengan kunjungan sebanyak 3560 orang.

Upaya peningkatan kesehatan lansia, khususnya peningkatan kualitas hidup lansia dengan melakukan olahraga secara rutin memiliki efek cukup positif pada kualitas hidup seseorang, khususnya pada lansia. Salah satu jenis olahraga yang bisa dilakukan pada lansia yaitu senam. Senam adalah serangkaian gerak nada yang teratur dan terarah serta terencana yang dilakukan secara tersendiri atau berkelompok dengan maksud meningkatkan kemampuan fungsional raga untuk mencapai tujuan tersebut. ${ }^{4}$

Meningkatnya jumlah lansia di dunia menandakan hidup manusia semakin sejahtera. Quality of Life (QOL) adalah istilah yang digunakan untuk mengukur kesejahteraan. Kesejahteraan menggambarkan seberapa baik perasaan seseorang terhadap lingkungan mereka, dan secara kolektif perasaan ini dapat dianggap sebagai $Q O L$. Kualitas hidup seseorang sangat erat kaitannya dengan pola makan dan dukungan dari keluarganya, makanan yang mereka makan serta dukungan dari keluarganya mempengaruhi kualitas hidup lansia. ${ }^{5}$

Dukungan dari keluarga sangat berperan dalam kehidupan lansia. Sebab peran keluarga mempengaruhi psikologi lansia yang dapat mempengaruhi perbaikan konsumsinya. Konsumsi makanan lansia memiliki hubungan positif dengan kepuasan hidup. Salah satu kepuasan hidup adalah terpenuhinya semua kebutuhan termasuk kebutuhan akan makanan yang dikonsumsi. ${ }^{5,6}$

Senam, Pola makan, dan dukungan keluarga merupakan salah satu tolak ukur terhadap kualitas hidup pada lansia. Penelitian ini bertujuan untuk mengetahui hubungan antara Senam, Pola Makan dan Dukungan Keluarga dengan Kualitas Hidup pada Lansia di UPTD Puskesmas Majalengka Kabupaten Majalengka.

\section{METODE PENELITIAN}

Penelitian ini merupakan penelitian kuantitatif dengan jenis penelitian survey research method (metode penelitian survey). Rancangan penelitain yang penulis pilih adalah potong silang (cross sectional). Variabel independen dalam penelitian ini 
adalah senam, pola makan, dan dukungan keluarga. Sedangkan variabel dependen yaitu kualitas hidup lansia.

Populasi pada penelitian ini yaitu lansia yang berusia 60 tahun ke atas yang berjumlah 2597 orang. Dari jumlah tersebut diambil sampel sebanyak 97 orang yang memenuhi kriteria inklusi dan diambil menggunakan teknik accidental sampling. Alat pengumpulan data yang digunakan dalam penelitian ini adalah dengan menggunakan kuesioner. Lokasi penelitian ini adalah di UPTD Puskesmas Majalengka Kabupaten Majalengka.

\section{HASIL PENELITIAN}

Kualitas Hidup, Senam, Pola Makan, Dan Dukungan Keluarga Lansia Di UPTD Puskesmas Majalengka Kabupaten Majalengka Tahun 2017

Tabel 1. Distribusi Frekuensi Kualitas Hidup, Senam, Pola Makan, Dan Dukungan Keluarga Lansia di UPTD Puskesmas Majalengka Kabupaten MajalengkaTahun 2017

\begin{tabular}{clcc}
\hline No & \multicolumn{1}{c}{ Kategori } & F (n=97) & Persentase (\%) \\
\hline 1 & Kualitas Hidup & 0 & 0 \\
& Rendah & 26 & 26,8 \\
& Sedang & 71 & 73,2 \\
& Tinggi & & \\
\hline 2 & Senam & 23 & 23,7 \\
\hline & Tidak Pernah & 13 & 13,4 \\
& Kadang-kadang & 61 & 62,9 \\
& Rutin & & 0 \\
\hline 3 & Pola Makan & 0 & 24,7 \\
\hline & Buruk & 24 & 75,3 \\
\hline & Normal & 73 & 0 \\
& Baik & & 23,7 \\
\hline & Dukungan Keluarga & 0 & 76,3 \\
\hline
\end{tabular}

Berdasarkan tabel 1 dapat dilihat bahwa dari 97 orang responden menunjukan lansia dengan kualitas hidup tinggi sebanyak 71 orang $(73,2 \%)$, lansia yang rutin mengikuti senam sebanyak 61 orang $(62,9 \%)$, lansia yang memiliki pola makan yang baik sebanyak 73 orang $(75,3 \%)$, dan lansia yang mendapatkan dukungan yang tinggi dari keluarganya sebanyak 74 orang $(76,3 \%)$.

\section{Hubungan Senam Dengan Kualitas Hidup Lansia di UPTD Puskesmas Majalengka Kabupaten MajalengkaTahun 2017}

Tabel 2. Hubungan Senam Dengan Kualitas Hidup Lansia di UPTD Puskesmas Majalengka Kabupaten MajalengkaTahun 2017

\begin{tabular}{|c|c|c|c|c|c|c|c|c|c|c|}
\hline \multirow{3}{*}{ No } & \multirow{3}{*}{ Senam Lansia } & \multicolumn{6}{|c|}{ Kualitas Hidup Lansia } & \multicolumn{2}{|c|}{ Jumlah } & \multirow{3}{*}{$p$ value } \\
\hline & & \multicolumn{2}{|c|}{ Rendah } & \multicolumn{2}{|c|}{ Sedang } & \multicolumn{2}{|c|}{ Tinggi } & \multirow[b]{2}{*}{$\mathrm{n}$} & \multirow{2}{*}{$\%$} & \\
\hline & & $\mathrm{n}$ & $\%$ & $\mathrm{n}$ & $\%$ & $\mathrm{n}$ & $\%$ & & & \\
\hline 1 & Tidak Pernah & 0 & 0 & 20 & 87 & 3 & 13 & 23 & 100 & \\
\hline 2 & Kadang-kadang & 0 & 0 & 4 & 30,8 & 9 & 69,2 & 13 & 100 & 0,000 \\
\hline 3 & Rutin & 0 & 0 & 2 & 3,3 & 59 & 96,7 & 61 & 100 & \\
\hline
\end{tabular}


Berdasarkan tabel 2 menunjukkan dari 97 responden yang diteliti, 23 orang yang tidak pernah melakukan senam pagi ternyata $87 \%$ memiliki kualitas hidup sedang dan dari 61 orang yang melakukan senam pagi secara rutin, 96,7\% memiliki kualitas hidup tinggi. Dari hasil uji statistik dengan menggunakan uji chi square didapatkan nilai $p$ value $=0,000$. Hal ini menunjukkan ada hubungan antara senam lansia dengan kualitas hidup lansia.

\section{Hubungan Pola Makan Dengan Kualitas Hidup Lansia di UPTD Puskesmas Majalengka Kabupaten MajalengkaTahun 2017}

Tabel 3. Hubungan Pola Makan Dengan Kualitas Hidup Lansia di UPTD Puskesmas Majalengka Kabupaten MajalengkaTahun 2017

\begin{tabular}{|c|c|c|c|c|c|c|c|c|c|c|}
\hline \multirow{3}{*}{ No } & \multirow{3}{*}{ Pola Makan } & \multicolumn{6}{|c|}{ Kualitas Hidup Lansia } & \multicolumn{2}{|c|}{ Jumlah } & \multirow{3}{*}{$p$ value } \\
\hline & & \multicolumn{2}{|c|}{ Rendah } & \multicolumn{2}{|c|}{ Sedang } & \multicolumn{2}{|c|}{ Tinggi } & \multirow{2}{*}{$\mathrm{n}$} & \multirow{2}{*}{$\%$} & \\
\hline & & $\mathrm{n}$ & $\%$ & $\mathrm{n}$ & $\%$ & $\mathrm{n}$ & $\%$ & & & \\
\hline 1 & Buruk & 0 & 0 & 0 & 0 & 0 & 0 & 0 & 0 & \\
\hline 2 & Normal & 0 & 0 & 20 & 83,3 & 4 & 16,7 & 24 & 100 & 0,000 \\
\hline 3 & Baik & 0 & 0 & 6 & 8,2 & 67 & 91,8 & 73 & 100 & \\
\hline
\end{tabular}

Berdasarkan tabel 3 menunjukkan dari 97 responden, 24 orang yang yang memiliki pola makan normal, 83,3\% memiliki kualitas hidup sedang, dan responden dengan pola makan yang baik $91,8 \%$ memiliki kualitas hidup tinggi. Dari hasil uji statistik dengan menggunakan uji chi square didapatkan nilai $p$ value $=0,000$. Hal ini menunjukkan ada hubungan antara pola makan lansia dengan kualitas hidup lansia.

\section{Hubungan Dukungan Keluarga Dengan Kualitas Hidup Lansia di UPTD Puskesmas Majalengka Kabupaten Majalengka Tahun 2017}

Tabel 4. Hubungan Dukungan Keluarga Dengan Kualitas Hidup Lansia di UPTD Puskesmas Majalengka Kabupaten MajalengkaTahun 2017

\begin{tabular}{|c|c|c|c|c|c|c|c|c|c|c|}
\hline \multirow{3}{*}{ No } & \multirow{3}{*}{$\begin{array}{c}\text { Dukungan } \\
\text { Keluarga }\end{array}$} & \multicolumn{6}{|c|}{ Kualitas Hidup Lansia } & \multicolumn{2}{|c|}{ Jumlah } & \multirow{3}{*}{$p$ value } \\
\hline & & \multicolumn{2}{|c|}{ Rendah } & \multicolumn{2}{|c|}{ Sedang } & \multicolumn{2}{|c|}{ Tinggi } & \multirow[b]{2}{*}{$\mathrm{n}$} & \multirow{2}{*}{$\%$} & \\
\hline & & $\mathrm{n}$ & $\%$ & $\mathrm{n}$ & $\%$ & $\mathrm{n}$ & $\%$ & & & \\
\hline 1 & Rendah & 0 & 0 & 0 & 0 & 0 & 0 & 0 & 0 & \\
\hline 2 & Sedang & 0 & 0 & 22 & 95,7 & 1 & 4,3 & 23 & 100 & 0,000 \\
\hline 3 & Tinggi & 0 & 0 & 4 & 5,4 & 70 & 94,6 & 74 & 100 & \\
\hline
\end{tabular}

Berdasarkan tabel 4 diperoleh data dari 97 responden, 23 orang yang mendapatkan dukungan keluarga sedang 95,7\% memiliki kualitas hidup sedang dan dari 74 responden dengan dukungan keluarga tinggi 94,6\% memiliki kualitas hidup tinggi. Dari hasil uji statistik dengan menggunakan uji chi square didapatkan nilai $p$ value $=0,000$. Hal ini menunjukkan ada hubungan antara dukungan keluarga dengan kualitas hidup lansia.

\section{PEMBAHASAN}

\section{Hubungan Se nam Dengan Kualitas Hidup Lansia di UPTD Puskesmas Majalengka Kabupaten Majalengka Tahun 2017}

Berdasarkan tabel 2 dapat dilihat bahwa dari 97 orang responden lansia menunjukan lansia yang tidak pernah mengikuti senam dan memiliki kualitas hidup sedang sebanyak 20 orang (87\%), sedangkan lansia yang tidak pernah mengikuti senam dan memiliki kualitas hidup tinggi sebanyak 3 orang (13\%). Lansia yang kadang-kadang mengikuti senam dan memiliki kualitas hidup yang sedang sebanyak 
4 orang $(30,8 \%)$, sedangkan lansia yang kadang-kadang mengikuti senam dan memiliki kualitas hidup yang tinggi sebanyak 9 orang $(69,2 \%)$. Lansia yang rutin mengikuti senam dan memiliki kualitas hidup yang sedang sebanyak 2 orang $(3,3 \%)$, sedangkan lansia yang rutin mengikuti senam dan memiliki kualitas yang tinggi sebanyak 59 orang $(96,7 \%)$. Hasil tersebut menunjukan bahwa proporsi lansia yang memiliki kualitas hidup tinggi lebih besar pada lansia yang rutin mengikuti senam dibandingkan yang kadang-kadang dan tidak pernah mengikuti senam. Dari hasil uji statistik dengan menggunakan uji chi square didapatkan nilai $p$ value $=0,000$. Hal ini menunjukkan ada hubungan antara senam lansia dengan kualitas hidup lansia.

Hal ini sejalan dengan penelitian Ringgit Pragista tentang Pengaruh Senam Lansia Terhadap Perubahan Tekanan Darah Lansia di Pobindu Desa Babakan Koda Kabupaten Majalengka yang mengatakan ada perbedaan tekanan darah sebelum dan sesudah senam Lansia di Pobindu Desa Babakan Koda Kabupaten Majalengka. ${ }^{7}$

Senam adalah serangkaian gerak tubuh yang teratur dan terarah serta terencana yang dilakukan secara tersendiri atau berkelompok. Dalam bahasa Inggris terdapat istilah exercise atau aerobic yang merupakan suatu aktifitas fisik yang dapat memacu jantung dan peredaran darah serta pernafasan yang dilakukan dalam jangka waktu yang cukup lama sehingga menghasilkan manfaat terhadap tubuh. ${ }^{8}$

\section{Hubungan Pola Makan Dengan Kualitas Hidup Lansia di PTDPuskesmas Majalengka Kabupaten Majalengka Tahun 2017}

Berdasarkan tabel 3 dapat dilihat bahwa dari 97 orang responden lansia menunjukan lansia dengan pola makan normal dan memiliki kualitas hidup sedang sebanyak 20 orang $(83,3 \%)$, sedangkan lansia dengan pola makan normal dan memiliki kualitas hidup tinggi sebanyak 4 orang $(16,7 \%)$. Lansia dengan pola makan baik dan memiliki kualitas hidup yang sedang sebanyak 6 orang $(8,2 \%)$, sedangkan lansia dengan pola makan baik dan memiliki kualitas hidup yang tinggi sebanyak 67 orang $(91,8 \%)$. Hasil tersebut menunjukan bahwa proporsi lansia yang memiliki kualitas hidup tinggi lebih besar pada lansia dengan pola makan yang baik dibandingkan lansia dengan pola makan yang normal dan buruk. Dari hasil uji statistik dengan menggunakan uji chi square didapatkan nilai $p$ value $=0,000$. Hal ini menunjukkan ada hubungan antara pola makan lansia dengan kualitas hidup lansia.

Hal ini sejalan dengan penelitian yang dilakukan oleh Yunita Puspita Sari (2016) "Gambaran Pola Makan, Status Gizi, Interaksi Sosial Dan Kualitas Hidup Lansia Di Wilayah Kerja Puskesmas Jongaya", menyatakan bahwa lansia yang mempunyai pola makan baik juga mempunyai kualitas hidup yang baik.

Pola makan atau pola konsumsi pangan adalah susunan jenis dan jumlah makanan yang dikonsumsi seseorang atau kelompok orang pada waktu tertentu. ${ }^{9}$

\section{Hubungan Dukungan Keluarga Dengan Kualitas Hidup Lansia di UPTD Puskesmas Majalengka Kabupaten Majalengka Tahun 2017}

Berdasarkan tabel 4 dapat dilihat bahwa dari 97 orang responden lansia menunjukan lansia dengan dukungan keluarga sedang dan memiliki kualitas hidup sedang sebanyak 22 orang $(95,7 \%)$, sedangkan lansia dengan dengan dukungan keluarga sedang dan memiliki kualitas hidup tinggi sebanyak 1 orang (4,3\%). Lansia dengan dukungan keluarga tinggi dan memiliki kualitas hidup yang sedang sebanyak 4 orang $(5,4 \%)$, sedangkan lansia dengan dukungan keluarga tinggi dan memiliki kualitas hidup yang tinggi sebanyak 70 orang $(94,6 \%)$. Hasil tersebut menunjukan bahwa proporsi lansia yang memiliki kualitas hidup tinggi lebih besar pada lansia yang mendapatkan dukungan tinggi dari keluarganya dibandingkan lansia yang 
mendapatkan dukungan sedang dan rendah dari keluarganya. Dari hasil uji statistik dengan menggunakan uji chi square didapatkan nilai $p$ value $=0,000$. Hal ini menunjukkan ada hubungan antara dukungan keluarga dengan kualitas hidup lansia.

Hal ini sejalan dengan penelitian Alnidi Safarach tentang "Gambaran Dukungan Keluarga Terhadap Pemanfaatan Posbindu Lansia Di Kelurahan Karasak Kota Bandung menyatakan lebih dari setengah responden memiliki dukungan keluarga yang mendukung dalam dukungan emosional dan instrumental terhadap lansia. ${ }^{10}$ lansia. ${ }^{11}$

Dukungan keluarga yang tinggi akan memberikan kenyamanan dan ketenangan pada

\section{KESIMPULAN}

1. Lebih dari setengahnya lansia rutin mengikuti senam di UPTD Puskesmas Majalengka Kabupaten Majalengka Tahun 2017.

2. Lebihdari setengahnya lansia mempunyai pola makan yang baik di UPTD Puskesmas Majalengka Kabupaten Majalengka Tahun 2017.

3. Sebagian besar lansia mendapatkan dukungan yang tinggi dari keluarganya di UPTD Puskesmas Majalengka Kabupaten Majalengka Tahun 2017.

4. Ada hubungan antara senam dengan kualitas hidup pada lansia di UPTD Puskesmas Majalengka Kabupaten Majalengka Tahun 2017.

5. Ada hubungan antara pola makan dengan kualitas hidup pada lansia di UPTDPuskesmas Majalengka Kabupaten Majalengka Tahun 2017.

6. Ada hubungan antara dukungan keluarga dengan kualitas hidup pada lansia di UPTD Puskesmas Majalengka Kabupaten Majalengka Tahun 2017.

\section{SARAN}

\section{Lahan Penelitian}

Untuk meningkatkan program senam lansia, puskesmas perlu meningkatkan pelayanan kesehatan khususnya terhadap klien lansia.

2. Petugas Kesehatan

Untuk meningkatkan minat lansia mengikuti senam lansia, perlu ada penambahan jenis-jenis senam agar lansia tidak merasakan kejenuhan dalam mengikuti senam lansia.

3. Keluarga dan Klien Lansia

Untuk keluarga lansia agar tetap memberikan perhatian, menjalin komunikasi yang baik, dan tetap memberikan dukungan kepada lansia.

\section{DAFTAR PUSTAKA}

1. Renjana, Era. Hubungan Profil Keluarga Dengan Pola Penyakit Pasien Keluarga Binaan Klinik Dokter Keluarga.Jakarta: FKUI;2009

2. Badan Pusat Statistik. Statistik Penduduk Lanjut Usia 2015. Jakarta: BPS; 2015

3. Badan Pusat Statistik Provinsi Jawa Barat. Jawa Barat dalam Angka 2015.Bandung: BPS;2015

4. Mohammad Rizal Pamungkas. Pengaruh Senam Bugar Lansia Terhadap Kualitas Lansia. Jurnal Kesehatan Olahraga. Vol.06 No. 2. Edisi Oktober 2016. Hal. 254-257; 2016

5. Desy, R, dkk. Hubungan Pola Makan, Status Gizi, Dan Interaksi Sosial Dengan Kualitas Hidup Lansia Di Kecamatan Tamalanrea.(jurnal online);2014

6. Rusilanti, Kusharto, Ahyuni E.S. Aspek Psikososial, Aktivitas Fisik, Dan Konsumsi Makanan Lansia Di Masyarakat. Jurnal Gizi Dan Pangan 1 (2), 1-7; 2006

7. Ringgit Pragista. Pengaruh Senam Lansia Terhadap Perubahan Tekanan Darah Lansia Di Posbindu Desa Babakan Koda Kabupaten Cirebon. 2015 
8. Suroto. Buku Pegangan Kuliah Pengertian Senam, Manfaat Senam Dan Urutan Gerakan. Semarang: Unit Pelaksana Teknis Mata Kuliah Umum Olahraga UNDIP;2007

9. Baliwati, Yayah F. Pengantar Pangan Dan Gizi. Jakarta: Penebar Swadaya;2004

10. Bratanegara, Alnidi Safarach. Gambaran Dukungan Keluarga Terhadap Pemanfaatan Posbindu Lansia Di Kelurahan Karasak Kota Bandung. Bandung: Fakultas Ilmu Keperawatan UNPAD;2012

11. Suardana, J.K. Dini, I.G.A.A., Kusmarjatni. Hubungan Dukungan Sosial Keluarga Dengan Kualitas Hidup Pasien DM Tipe 2 Di Puskesmas Denpasar. Bali: Jurnal Jurnal Skala Husada $12(1), 96-102 ; 2015$ 